\title{
ERECTOR SPINAE PLANE BLOCK FOR POSTOPERATIVE ANALGESIA AFTER VATS: A SAFE AND EFFECTIVE ALTERNATIVE TO EPIDURAL ANALGESIA
}

Catalá Ripoll JV, Sánchez López ML, Martínez Vilar C, Cuesta Montero P, Monsalve Naharro JA, Rodriguez Gimillo P.

\section{INTRODUCTION}

Postoperative pain increases the morbidity and mortality after surgery. It gains importance in thoracic surgery, because the rehabilitation is essential in the initial postoperative period. For this reason, alternative analgesic techniques to the epidural are useful for cases in which epidural wasn't possible.

\section{CASE REPORT}

Fifty years old woman scheduled for right inferior lobectomy by VATS. In this case, epidural catheter couldn't be possible due to a osteoporotic fracture at spinous process of the fifth and sixth thoracic vertebras. We performed an ESP blocks at the T5 level. About 3 centimeters lateral to the transverse process of T5 localizated the rhomboid, trapezius and erector spinal muscles. The inferior fascia of the erector muscle of the spine was located with a Tuhoy needle. We administrated $25 \mathrm{cc}$ of levobupivacaine $0.5 \%$ to dissect the interfascial space and placed a catheter at this level. We used analgesia by the catheter in the intraoperatory and first three postoperative days. Postoperative pain was less than 4 over 10 in VAS, during the postoperative period.

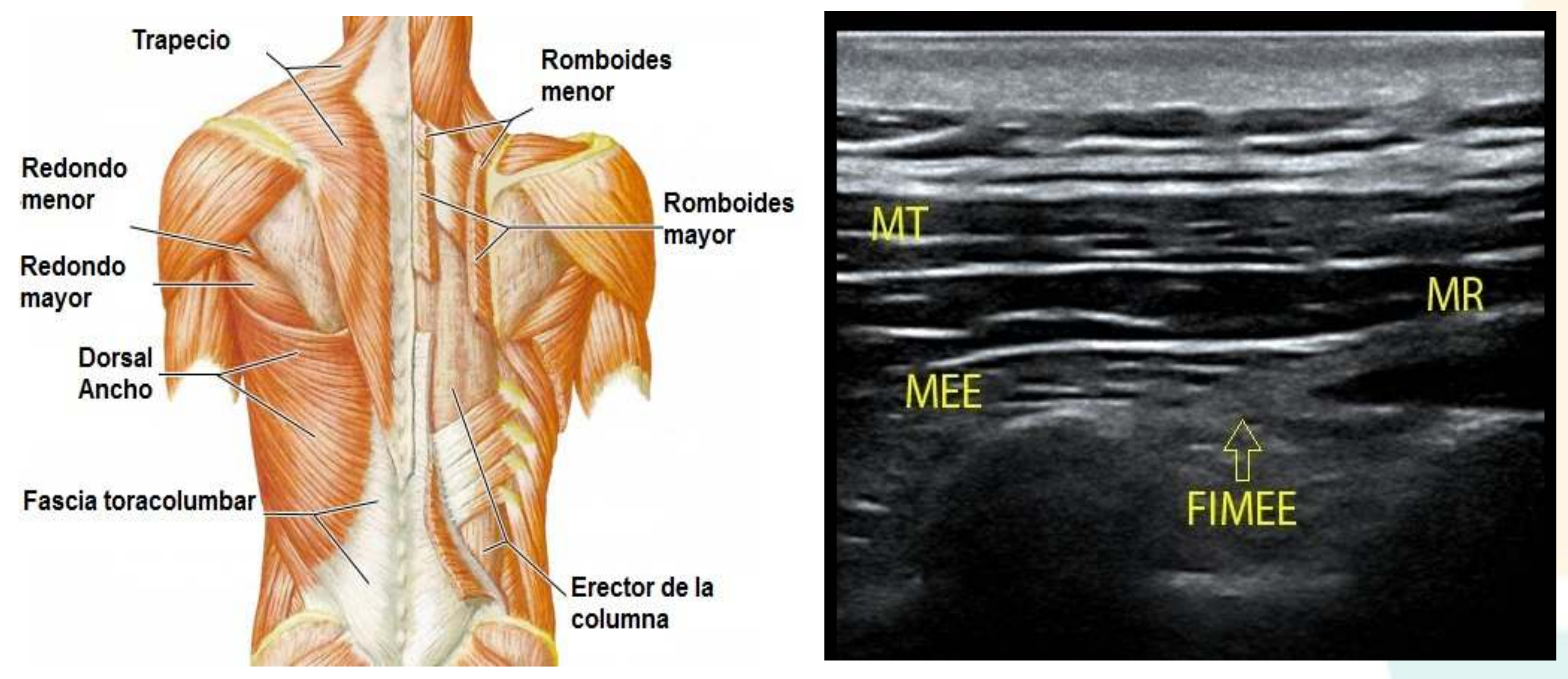

\section{CONCLUSIONS}

The erector spinae plane block is a simple technique of postoperative analgesia, easily reproducible with an adequate safety profile that allows a good analgesic control in postoperative pain after videothoracoscopy. 